\title{
Mycobacterium microti
}

National Cancer Institute

\section{Source}

National Cancer Institute. Mycobacterium microti. NCI Thesaurus. Code C85548.

A species of Mycobacterium that is a member of the Mycobacterium tuberculosis complex. It is the causative agent of tuberculosis in voles. 